\title{
UNA NUEVA ESPECIE DE PACHYCEREUS
}

\author{
Por Helia BRAVO $\mathrm{H}$.
}

La nueva especie que aquí se describe crece en la zona del Istmo de Tehuantepec y es muy parecida al Pachycereus grandis Britt. et Rose, con el cual se ha confundido. El Sr. Thomas MacDougall observó y anotó las diferencias que los separan y tomó algunas fotografías. En el mes de enero de este año colecté algunos ejemplares y la comparación que he hecho de ellos con los de $P$. grandis de la Barranca de Atoyac, Pue., me condujo a la conclusión de que se trata de especies diferentes.

Pachycereus tehuantepecanus Th. MacDougall et H. Bravo H. Cactáceas y Suculentas Mexicanas I. Núm. 4. p. 64. Abril-junio de 1956.

Cactácea arborescente de 10-15 m. de altura o algo más. Tallo cilíndrico de unos $2 \mathrm{~m}$. de largo por 0.50 de diámetro, con ramificación basítona; ramas numerosas, columnares y simples, de 15 a $20 \mathrm{~cm}$. de diámetro; costillas de 9 a 11, triangulares y rectas, con arista bien defini$\mathrm{da}$, de 3 a $5 \mathrm{~cm}$., de color verde claro levemente amarillento y con ligero tinte pruinoso en la región de crecimiento. Areolas de la región vegetativa distantes de 2 a $2.5 \mathrm{~cm}$., elípticas, de un centímetro de largo y con fieltro grisáceo. Espinas radiales de 5 a 8, subuladas, de 1.5 a $2 \mathrm{~cm}$., con la punta negra. A veces hay en la parte inferior de la areola un grupo de espinas ( 2 ó 3) pequeñas. Espinas centrales generalmente una, subuladas, más larga que las radiales y de longitud variable, frecuentemente de unos $4.5 \mathrm{~cm}$., recta, perpendicular a la areola y de igual color que las radiales. Las areolas floríferas están distantes entre sí un centímetro y son elípticas, de $1.5 \mathrm{~cm}$. de largo, con lana de color café claro y unas 50 cerdas gruesas y pungentes de $2 \mathrm{~cm}$. de largo, al principio amarillentas o morenas y después grisáceas Flores diurnas, de 9.5 a $12 . \mathrm{cm}$. de largo por 7 de ancho, tubular-infundibuliformes; superficie exterior del ovario con numerosas areolas provistas de una escama pequeña con abundante lana de color café claro que oculta la superficie del ovario, y algunas cerdas amarillentas que se desarrollan cuando el ovario se transforma en fruto; la superficie externa del tubo es de color moreno verdoso y lleva podarios alargados que dan al tubo un aspecto estriado; la escama de éstos es triangular y acuminada, de 5 a $18 \mathrm{~mm}$. de longitud y de color purpúreo; en la axila tiene algunas cerdas y numerosos pelos lanosos que en parte cubren la superficie del tubo; el perianto os reflejado, con los segmentos exteriores cortamente espatulados, de $2.5 \mathrm{~cm}$. de 


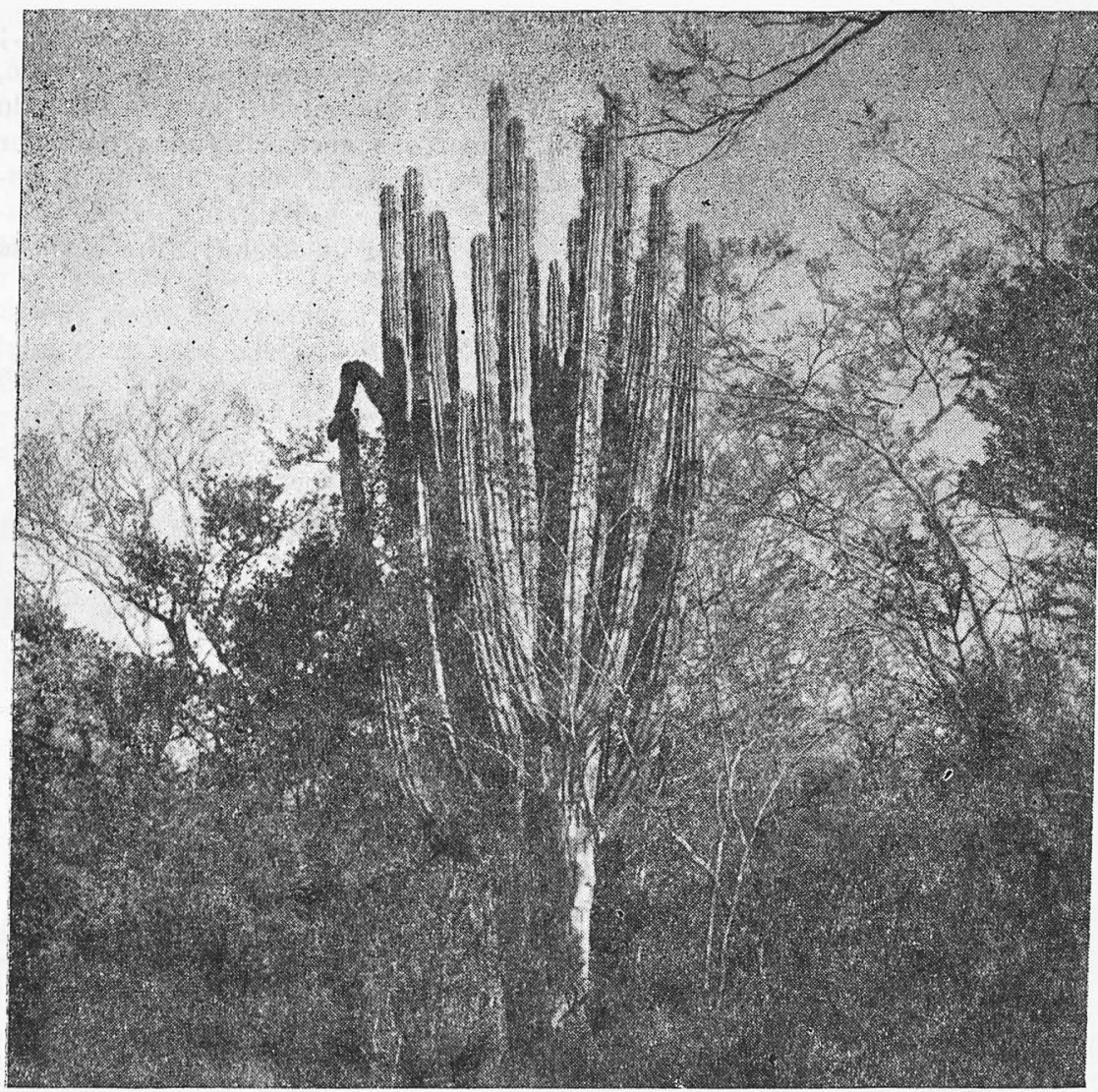

ASPECTO GENERAL

largo por $9 \mathrm{~mm}$. de ancho, de color moreno verdoso; segmentos interiores dispuestos en cuatro series, largamente espatulados, algo lobulados cerca del ápice y de color blanquecino al principio y después negruzco. En un corte longitudinal de la flor se observa la cavidad del ovario la cual es oval o casi circular, de unos $6 \mathrm{~mm}$. de diámetro o algo más; los óvulos están insertos en funículos ramificados; la cavidad nectarial mide unos $2 \mathrm{~cm}$. de largo por 1.5 de ancho, estriada longitudinalmente; las paredes del tubo son engrosadas y miden unos $8 \mathrm{~mm}$. Los estambres son numerosos y están colocados a lo largo de la pared del tubo a partir del nectario; los filamentos son blanquecinos y muy delgados cerca de la antera; los de la región basal son largos y encorvados de manera que cierran el nectario; los que están insertados en la garganta son más cortos; anteras de color amarillo pálido; el estilo es blanquecino de unos $6 \mathrm{~cm}$ de largo y 
llegan a la misma altura que las anteras o las sobrepasan unos $5 \mathrm{~mm}$.; los lóbulos del estigma son de color crema y claviformes. Fruto espinoso, globular, al fin deshiscente, de 10 a $15 \mathrm{~cm}$. de diámetro o más incluyendo las espinas; areolas persistentes, con numerosas cerdas agudas de color pajizo, algunas hasta de $6 \mathrm{~cm}$. de largo que ocultan completamente la superficie. Semillas numerosas, con la testa negra y brillante, algo aplanadas lateralmente, de 5 a $6 \mathrm{~mm}$. de largo por 4 de ancho; hilio carnoso y purpurino.

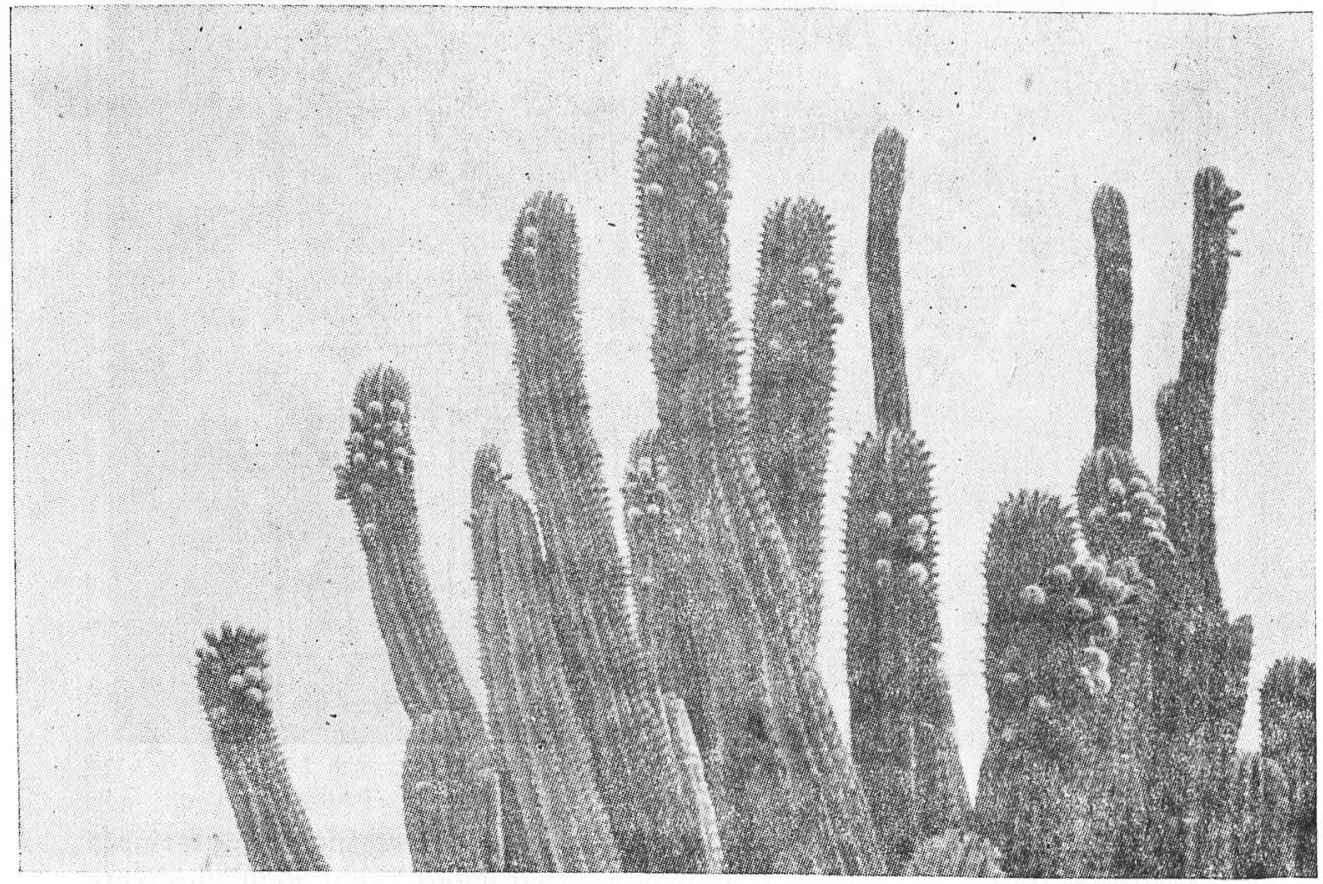

RAMAS CON FLORES

Distribución: Istmo de Tehuantepec desde Totolapan hasta cerca de Cuicatlapa, en selva tropical decidua. Tipo colectado en Juchitán, Oax., y depositado en el Herbario Nacional de México. 